\title{
Antidiabetic Effect of Pumpkin Seeds and Gum Arabic and/or Vildagliptin on type 2 Induced Diabetes in Male Rats
}

\author{
Mohamed F Dowidar ${ }^{1}$, Amany I Ahmed ${ }^{1}$ and Hanaa R Mohamed ${ }^{2 *}$ \\ ${ }^{1}$ Department of Biochemistry, Faculty of Veterinary Medicine, Zagazig University, 44519 Zagazig, Egypt \\ ${ }^{2}$ Faculty of Pharmacy, Zagazig University, 44519 Zagazig, Egypt \\ *Corresponding author: h.7mmad4288@gmail.com
}

\begin{abstract}
Article History: 19-699 Received: November 10, 2019 Revised: December 31, 2019 Accepted: January 06, 2020
ABSTRA CT

Metabolic syndrome is the accompaniment of multiple risk factors for atherosclerotic cardiovascular disease and type 2 diabetes (T2D) including glucose intolerance, hypertension and dyslipidemia where obesity is the basic element at this syndrome. T2DM is a heterogeneous metabolic syndrome resulting from genomic-environment complex interaction. Pumpkin seeds and gum Arabic are two natural products with an obvious hypoglycemic role. Vildagliptin is a selective inhibitor of dipeptidylpeptidase-4 (DPP-IV), and a certified therapy for T2DM. This study has been destined to assess in vivo the hypoglycemic impact of pumpkin seeds and gum Arabic in compare with vildagliptin and their combination treatments. 70 male albino rats were randomly separated into seven groups of ten each: control nondiabetic, control non-treated diabetic, diabetic treated with pumpkin seed extract (300mg/kg/day), diabetic treated with gum Arabic $(500 \mathrm{mg} / \mathrm{kg} /$ day), diabetic treated with vildagliptin $(10 \mathrm{mg} / \mathrm{kg} /$ day), diabetic treated with a combination of pumpkin seed extract and vildagliptin, and diabetic treated with a combination of gum Arabic and vildagliptin.T2DM was stimulated by feeding rats on high fat-high fructose/sucrose diet regimen (HFHF/S) for 12 weeks. Biochemical assessment has revealed that pumpkin seed extract, gum Arabic and vildagliptin can alleviate the severity of hyperglycemia, insulin resistance, dyslipidemia and depress glucagon secretion.
\end{abstract}

Key words: Type 2 diabetes, Insulin resistance, Pumpkin seeds, Gum Arabic, Vildagliptin

\section{INTRODUCTION}

Type 2 diabetes and its complications constitute a serious worldwide health problem; it is the predominant form of diabetes mellitus as it poses about $90 \%$ of all diabetic cases (Ozougwu et al., 2013). T2DM ascends significantly with obesity, genetic and epigenetic factors, while pathogenesis principally occurs when feedback circuits between insulin secretion by $\beta$-cells and insulin action cannot labor appropriately, leading to rising up in fasting and post-prandial blood glucose levels. The insulin resistance is correlated with morbidity in glucose uptake of the insulin-sensitive tissue with abnormal elevation of hepatic glucose production (HGP) via gluconeogenesis or glycogenolysis, hepatic triglyceride content (HTG) and free fatty acids (FFA) levels with imbalance of adipocytokines in adipose tissue. Alongside pancreatic $\beta$ cells secrete abnormal high levels of insulin to control hyperglycemia but by the time, hyperglycemia and hyperinsulinemia result in $\beta$-cell dysfunction and dependent gradual damage (Stumvoll et al., 2005).
Nowadays, search and exploring natural plants with medicinal effects have been highlighted all over the world, in an attempt to avert adverse effects and toxicity of the synthetic medication (Patel et al., 2012a). Pumpkins belong to "Cucurbitaceae" plant family. Pumpkin is well-known for its eaten fruit and seeds. Pumpkin seeds are greatly nutritional with high protein and essential fatty acids contents (Yadav et al., 2010). Pumpkin seed oil is highly unsaturated with major content of oleic and linoleic acids, the most critical therapeutic effect of pumpkin seed oil is the inhibition of prostate hyperplasia and suppression of bladder and urethral pressure, also can alleviate hypertension and hypercholesterolemia (Dar et al., 2017). Pumpkin seeds include moderate amounts of minerals, particularly phosphorus, potassium and magnesium, and relatively high amounts of other minerals such as iron, copper, calcium, zinc, sodium and manganese, these elements boost the pumpkin seed value as a food supplement (Glew et al., 2006). Pumpkin seed extracts possess antidiabetic, antioxidant, antihyperlipidemic, antitumor and antihypertensive actions, These therapeutics

Cite This Article as: Dowidar MF, AI Ahmed and HR Mohamed, 2020. Antidiabetic effect of pumpkin seeds and gum arabic and/or vildagliptin on type 2 induced diabetes in male rats. Int J Vet Sci, 9(2): 229-233. www.ijvets.com (@2020 IJVS. All rights reserved) 
are attributed to the abundant presence of proteins, lignans, triterpenes, carotenoids, phytosterols, tocopherols and flavonoids (Gohari Ardabili et al., 2011), among these phenolics: D-chiro-inositol, trigonelline and nicotinic acid; which are considered as insulin action mediators (insulin sensitizers) (Adams et al., 2014).

Gum Arabic (GA) belongs to "Fabaceae" plant family, also known as gum acacia. GA is a dehydrated sticky exudate gained mainly from the stems and branches of Acacia Senegal, it is water-soluble dietary fibers, consists principally of polysaccharides with high-molecular weight and their magnesium, calcium and potassium salts, the viscosity effect of these fibers relays digestion and absorption of carbohydrates, regulating glycemic index and body weight reduction (Babiker et al., 2018). GA is considered an important natural product with antioxidant, antihyperlipidemic and hypoglycemic action roles (Ibrahim et al., 2013). GA suppresses absorption of glucose in the intestine via interaction with membrane abundance of sodium-glucose transporter-1 (SGLT1) in experimental mice (Nasir et al., 2016).

Vildagliptin is a selective and reversible inhibitor of dipeptidylpeptidase-4 (DPP-IV), it binds covalently to the catalytic site of the enzyme, DPP-IV regulates incretin hormones which are glucose-dependent insulinotropic polypeptide (GIP) and glucagon-like peptide-1 (GLP-1), incretins regulate post-prandial glycemia, secreted in response to diet intake to stimulate insulin secretion in a glucose-dependent method and delay gastric emptying. Vildagliptin prevent rapid degradation of endogenous incretins, resulting in elevating plasma concentrations of their intact forms (Deacon and Holst, 2013). Vildagliptin induced elevated GLP-1 leads to boosting sensitivity of $\beta$ cells to blood glucose level and enhancing glucosedependent insulin secretion, vildagliptin induced elevated GLP-1 also enhances $\alpha$-cell sensitivity to glucose level, leading to reduction in post-prandial glucagon release without affecting the $\alpha$-cell response towards hypoglycaemia (Keating, 2014).

Our search aimed to evaluate the antidiabetic effect of pumpkin seed ethanolic extract and gum Arabic comparing with vildagliptin (standard antidiabetic), in addition to their combinations, in type 2 diabetic rat model, and their effects on some biochemical parameters.

\section{MATERIALS AND METHODS}

\section{Preliminary materials}

Pumpkin seeds, gum Arabic powder and sucrose were purchased from trusted local market, purified and screened out from any impurities. Vildagliptin was obtained in the form of Galvus 50mg tablets from Hikma Pharmaceuticals, Egypt. Lard purchased from El Basateen Slaughterhouse, Egypt. Fructose purchased from El Gomhoureya Company for Drugs Trade\& Medical supplies, Egypt.

\section{Extract preparation}

Pumpkin seeds were washed with water and desiccated in a place away from direct sunlight. At complete drying, the seeds were well crushed till obtaining fine powder then extracted by soxhlet apparatus with $70 \%$ ethanol as solvent. Ethanol is eliminated under reduced- pressure, yielding a solid residue which stored at $4^{\circ} \mathrm{C}$ till use (Sharma et al., 2013).

\section{Experimental animals}

70 healthy adult male albino rats (100-150 g body weight) were purchased from the central animal house of Faculty of Veterinary Medicine, Zagazig University, Egypt. Rats were adapted for 2 weeks under standard laboratory conditions before any treatments, kept at a moderate temperature of $20-25^{\circ} \mathrm{C}, 12$-hour light-dark cycle and free access to food and water. After accommodation period, rats were randomly partitioned into two groups. The first group involved 10 rats and treated as a normal control group (G1) which fed on standard rat chow and pure water.

\section{Induction of type 2 diabetes}

The induction of type 2 diabetes was performed on the second group (G2) which included 60 rats supplied with high fat high fructose (HFHF) diet. HFHF consists of lard $(60 \%)$, and fructose $(17 \%)$ provided to the standard rat chow and sucrose (10\%) added to drinking water, these rats were housed for 12 weeks (de Castro et al., 2013). Body weight, as well as fasting blood glucose and serum insulin of rats were monitored weekly. After 12 weeks, rats became hyperglycemic with fasting blood glucose $\geq 200 \mathrm{mg} / \mathrm{dl}$, exhibited hyperinsulinemia and insulin resistant which confirmed by using a homeostasis model assessment of insulin resistance (HOMA-Insulin Resistance Index; HOMA-IR)

\section{Experimental design}

Control group (G1): normal rats fed on standard rat chow and drinking water.

Diabetic group (G2) was sub-partitioned into six subgroups according to their treatments as following:

Group I: high fat diet-induced diabetic rats without any treatments.

Group II: diabetic rats treated with pumpkin seed ethanolic extract (300mg/kg) (Marbun et al., 2018).

Group III: diabetic rats treated with gum Arabic (500mg/kg) (Almohaimeed et al., 2018).

Group IV: diabetic rats treated with vildagliptin $(10 \mathrm{mg} / \mathrm{kg})$ (Burkey et al., 2005).

Group V: diabetic rats treated with mixture of pumpkin seed extract and vildagliptin. Group VI: diabetic rats treated with mixture of gum Arabic and vildagliptin.

All treatments administered once daily and orally for 4 weeks. The dose was adjusted weekly according to weight changes to maintain the symmetry of dosage per $\mathrm{kg}$ of body weight in rats throughout the whole duration of the experiment.

\section{Blood samples}

After 4 weeks of treatments, all rats were decollated, blood samples were collected from orbital venous plexus and serum was separated by centrifugation at $3000 \mathrm{rpm}$ for 20 mins, the resultant supernatant were collected to be freshly forwarded to laboratory for biochemical parameters assessment.

\section{Biochemical analysis}

Assessment of serum glucose by oxidase method using spectrum diagnostics glucose kit (El-Gayar et al., 2012), 
Serum insulin by using Elisa rat insulin kits method (Wang et al., 2013). Total cholesterol evaluated by cholesterol liquizyme CHOD-PAP enzymatic colorimetric method (Penttilä et al., 1981), serum LDL-c and HDL-c by using the direct enzymatic colorimetric liquid method (Young and Friedman, 2001), VLDL-c by using Friedewald method (Fridewald, 1972), triacylglycerol (TAG) by GPOPAP-enzymatic colorimetric method (Bucolo and David, 1973) and serum glucagon by using Mercodia Glucagon ELISA kits method (Wewer Albrechtsen et al., 2016).

\section{Statistical analysis}

Statistical analysis was preceded using one-way ANOVA followed by post hoc Duncan's multiple range tests by SPSS 16 (SPSS, Chicago, Ill). Data were articulated as mean \pm SEM and $\mathrm{P}<0.05$ was statistically significant.

\section{RESULTS}

Effect of supplied pumpkin seed extract, gum Arabic and/or vildagliptin on the glycemic index and HOMAIR

As displayed in Table 1, supplying rats with HFHF diet induced type-2 diabetes with remarkable elevated glucose and insulin levels with insulin resistance compared to the normal control group. However, pumpkin seed extract, gum Arabic and vildagliptin treatments extenuated the intensity of hyperglycemia and hyper-insulinemia to a great extent, mostly in treatment combination groups. The insulin resistance degree was measured at the baseline by an insulin score (HOMA-IR). Low value of HOMA-IR results indicates boosting in insulin sensitivity, while high value indicates suppressed insulin sensitivity. In current results, HOMA-IR value was within normal in healthy control group then significantly increased in diabetic control group, and significantly reduced near to normal results at diabetic treated groups, indicating the impressive antidiabetic effect of pumpkin seed and gum Arabic and their synergistic effects with vildagliptin, giving better results.

\section{Effect of pumpkin seed extract, gum Arabic and/or vildagliptin on serum glucagon}

As displayed in Table 1, the diabetic control group showed elevated serum levels of glucagon, indicating its abnormal secretion, while the treated groups showed a significant reduction in glucagon secretion, particularly in combined-treated groups, referring to improvement of improperly high glucagon levels that characterize type 2 diabetes and amelioration of the insulin: glucagon ratio.

\section{Effect of pumpkin seed extract, gum Arabic and/or vildagliptin on serum lipid profile.}

As displayed in Table 2, the diabetic control group exhibited significant dyslipidemia which described by elevation of serum TC, TAG, LDL-C and VLDL-C, and reduction in HDL-C levels, comparing to the normal control group. However, diabetic groups treated with pumpkin seed extract, gum Arabic and/or vildagliptin exhibited a significant amelioration in the high fat dietinduced dyslipidemia.

\section{DISCUSSION}

The ethnobotanical knowledge has registered almost 800 plants that may have antidiabetic potential (Patel et al., 2012a; Patel et al., 2012b). According to Adams et al. (2014) studies, pumpkin seeds' antidiabetic activity is probably due to abundant presence of the efficient phytochemical compounds including: D-chiroinositol, trigonelline and nicotinic acid, their possible mechanisms affects $\beta$-cell regeneration and activities of enzymes involved in glucose metabolism, and in conjunction with Larner (2000) study which explained that D-chiro-inositol supposed to be a potent mediator of intracellular insulin action, through stimulating the dephosphorylation of glycogen synthase, pyruvate dehydrogenase and rate limiting enzymes of oxidative and non-oxidative glucose metabolism, deducing that supplying of D-chiro-inositol or natural extract containing D-chiro-inositol to diabetic experimental rats and now to humans can stimulate glucose metabolism and sensitize insulin action. Also trigonelline, a plant alkaloid, has hypoglycemic and hypolipidemic significance; Yoshinari et al. (2009) showed that trigonelline and nicotinic acid in pumpkin seeds could improve efficacy of the enzymes involved in glucose metabolism; glucokinase and glucose-6-phosphatase regulation. Other study suggested that the hypoglycemic potential of pumpkin seed may attribute to its rich protein components with molecular weight range (3-60 kDa) that may increase blood insulin level and improve blood glucose tolerance (Caili et al., 2006). the results of this study have revealed that pumpkin seed ethanolic extract well improved the glycemic index and total lipid profile, agreeing with Sharma et al. (2013) that explained the antidiabetic and antihyperlipidemic activity of three different extracts of pumpkin seeds which are petroleum ether, ethyl acetate and ethanol, however the ethanolic extract gave the most desirable results. In a comparison between the pumpkin flesh and seeds, Marbun et al. (2018) showed the significant hypoglycemic of their ethanolic extracts, where the seeds extract revealed higher hypoglycemic results than flesh, which nearly the same as metformin, and attributed the antidiabetic effect of these extracts to the phytochemical constituents like flavonoids, illustrating the mechanism maybe through stimulating the pancreatic $\beta$-cell insulin secretion, or the flavonoids can protect DNA from oxidative damage.

Gum Arabic (GA) possesses antioxidant, antihyperlipidemic and antidiabetic effects, Mirghani et al. (2018) performed appropriate antioxidant measurements on GA methanolic extract to detect the prescence of total phenolic compounds, ferric reducing power and cupric reducing capacity of GA samples. This antioxidative capacity enables GA to exert a nephron-protective effect against gentamicin-induced nephrotoxicity (Al-Majed et al., 2002), and cisplatin-induced nephrotoxicity in rats (AlMajed et al., 2003). In the current study, the high fat dietdiabetic rats supplied with GA had a significantly improved total lipid profile, these findings are in line with previous studies that showed the high ingestion of dietary fiber including GA is associated with significant reduction in body weight, visceral adipose tissue and improved lipid metabolism (Ahmed et al., 2016). Lattimer and Haub (2010) explained the mechanism as GA solution increases 
Int J Vet Sci, 2020, 9(2): 229-233.

Table 1: Means \pm SEM of serum levels of fasting blood glucose, insulin, HOMA-IR and glucagon in rats fed high fat high fructose diet and treated with pumpkin seeds, gum Arabic and/ or vildagliptin

\begin{tabular}{lcrrrrrr}
\hline Parameter & $\begin{array}{c}\text { Normal } \\
\text { control }\end{array}$ & $\begin{array}{c}\text { Diabetic } \\
\text { control }\end{array}$ & $\begin{array}{c}\text { Pumpkin seed } \\
\text { extract }\end{array}$ & Gum Arabic & Vildagliptin & $\begin{array}{r}\text { Vildagliptin } \\
\text { \& extract }\end{array}$ & $\begin{array}{c}\text { Vildagliptin } \\
\& \text { gum }\end{array}$ \\
\hline Glucose $(\mathrm{mg} / \mathrm{dl})$ & $82.8 \pm 0.75^{\mathrm{g}}$ & $221.5 \pm 0.94^{\mathrm{a}}$ & $160.15 \pm 0.33^{\mathrm{c}}$ & $177.4 \pm 0.78^{\mathrm{b}}$ & $135.4 \pm 0.54^{\mathrm{d}}$ & $103.95 \pm 0.22^{\mathrm{f}}$ & $116.3 \pm 0.11^{\mathrm{e}}$ \\
Insulin $(\mu \mathrm{U} / \mathrm{ml})$ & $8.02 \pm 0.45^{\mathrm{e}}$ & $12.45 \pm 0.52^{\mathrm{a}}$ & $11.12 \pm 0.33^{\mathrm{b}}$ & $11.89 \pm 0.23^{\mathrm{b}}$ & $10.33 \pm 0.17^{\mathrm{c}}$ & $9.84 \pm 0.72^{\mathrm{d}}$ & $10.02 \pm 0.45^{\mathrm{c}}$ \\
Homa_IR & $1.6 \pm 0.22^{\mathrm{f}}$ & $6.8 \pm 0.25^{\mathrm{a}}$ & $4.4 \pm 0.33^{\mathrm{c}}$ & $5.2 \pm 0.21^{\mathrm{b}}$ & $3.5 \pm 0.18^{\mathrm{d}}$ & $2.5 \pm 0.65^{\mathrm{e}}$ & $2.6 \pm 0.35^{\mathrm{e}}$ \\
Glucagon $(\mathrm{pg} / \mathrm{ml})$ & $40.83 \pm 0.54^{\mathrm{f}}$ & $106.74 \pm 0.44^{\mathrm{a}}$ & $70.75 \pm 0.64^{\mathrm{c}}$ & $89.62 \pm 0.58^{\mathrm{b}}$ & $65.52 \pm 0.31^{\mathrm{cd}}$ & $50.83 \pm 0.43^{\mathrm{e}}$ & $55.97 \pm 0.41^{\mathrm{de}}$ \\
\hline
\end{tabular}

$\overline{\text { Abcdefg }}$ Means \pm SEM at the same row and bearing different superscripts are significantly different at $\mathrm{P} \leq 0.05$.

Table 2: Means \pm SEM of lipid profile (TC-TAG-HDL-LDL-VLDL) in rats fed high fat high fructose diet and treated with pumpkin seeds, gum Arabic and/ or vildagliptin

\begin{tabular}{lrrrrrrr}
\hline Parameter & \multicolumn{1}{c}{$\begin{array}{c}\text { Normal } \\
\text { control }\end{array}$} & \multicolumn{1}{c}{$\begin{array}{c}\text { Diabetic } \\
\text { control }\end{array}$} & $\begin{array}{c}\text { Pumpkin } \\
\text { seed extract }\end{array}$ & \multicolumn{1}{c}{$\begin{array}{c}\text { Gum } \\
\text { Arabic }\end{array}$} & Vildagliptin & $\begin{array}{c}\text { Vildagliptin } \\
\text { \&extract }\end{array}$ & $\begin{array}{c}\text { Vildagliptin } \\
\text { \&gum }\end{array}$ \\
\hline Total cholesterol $<(\mathrm{mg} / \mathrm{dl})$ & $185.5 \pm 0.95^{\mathrm{f}}$ & $361 \pm 0.78^{\mathrm{a}}$ & $282.5 \pm 0.33^{\mathrm{bc}}$ & $306 \pm 0.30^{\mathrm{b}}$ & $256.5 \pm 0.02^{\mathrm{cd}}$ & $214.5 \pm 0.21^{\mathrm{e}}$ & $237.50 \pm 0.75^{\mathrm{de}}$ \\
Triacylglycrol $(\mathrm{mg} / \mathrm{dl})$ & $138.2 \pm 0.44^{\mathrm{g}}$ & $279.1 \pm 0.78^{\mathrm{a}}$ & $230.5 \pm 0.42^{\mathrm{c}}$ & $255.5 \pm 0.27^{\mathrm{b}}$ & $212.2 \pm 0.46^{\mathrm{d}}$ & $168.5 \pm 0.17^{\mathrm{f}}$ & $193.66 \pm 0.33^{\mathrm{e}}$ \\
HDL-c $(\mathrm{mg} / \mathrm{dl})$ & $68.5 \pm 0.44^{\mathrm{a}}$ & $24.1 \pm 0.73^{\mathrm{e}}$ & $39.1 \pm 4.61^{\mathrm{d}}$ & $31.2 \pm 0.15^{\mathrm{e}}$ & $49.2 \pm 0.46^{\mathrm{c}}$ & $61.5 \pm .86^{\mathrm{ab}}$ & $56.6 \pm 0.45^{\mathrm{b}}$ \\
LDL-c $(\mathrm{mg} / \mathrm{dl})$ & $89.4 \pm 0.84^{\mathrm{f}}$ & $281.2 \pm 0.13^{\mathrm{a}}$ & $194.4 \pm 0.42^{\mathrm{c}}$ & $223.9 \pm 0.78^{\mathrm{b}}$ & $165.1 \pm 0.75^{\mathrm{d}}$ & $119.3 \pm 0.71^{\mathrm{e}}$ & $142.3 \pm 0.44^{\mathrm{de}}$ \\
VLDL-c $(\mathrm{mg} / \mathrm{dl})$ & $27.6 \pm 0.80^{\mathrm{g}}$ & $55.8 \pm 0.61^{\mathrm{a}}$ & $46.1 \pm 0.40^{\mathrm{c}}$ & $51.1 \pm 0.63^{\mathrm{b}}$ & $42.4 \pm 0.69^{\mathrm{d}}$ & $33.7 \pm 0.63^{\mathrm{f}}$ & $38.7 \pm 0.86^{\mathrm{e}}$ \\
\hline
\end{tabular}

Abcdefg Means \pm SEM at the same row and bearing different superscripts are significantly different at $\mathrm{P} \leq 0.05$.

the viscosity of the intestinal contents, interferes with the nutrients absorption, forming micelle, that in turn, decreases lipid absorption from the intestine. Another mechanism suggested that GA soluble fibers may disrupt the enterohepatic circulation of the bile acids, leading to increase in bile acid excretion thus lower plasma cholesterol levels (Musa et al., 2019). A clinical trial based on daily supplement with powdered GA to healthy, prediabetics and type- 2 diabetic volunteers, the results revealed a significant decrease in fasting blood glucose and glycosylated hemoglobin (HbAc1) levels (Nasir et al., 2016). In accordance, the present study revealed an improved glycemic index and reduced glucagon level in GA treated HFHF diet-diabetic rats.

Vildagliptin is certified and widespread in more than 110 countries as a monotherapy or in a combination for type 2 diabetic-patients. Given the loss of response to GIP in type 2 diabetes, the glycemic effect of DPP-4 inhibitors has been considered largely GLP-1 related. Vildagliptin boosts GLP-1 levels, glucose-dependent insulin secretion and $\alpha$-cell sensitivity to glucose leading to suppression of post-prandial glucagon release. Not only post-prandial glucose level is decreased by vildagliptin, but also can affect the basal glucose. It is authenticated that suppression in basal hyperglycaemia noticed with vildagliptin, reflects extended overnight elevation in GLP-1 levels, resulting in extended suppression of hepatic glucose synthesis overnight (Keating, 2014). A research discussed the effect of vildagliptin on lipid profile of type- 2 diabetic patients, showing a significant reduction in total cholesterol levels (Maeda et al., 2012), also Matikainen et al. (2006) showed that a tablet of vildagliptin $50 \mathrm{mg}$ twice daily significantly reduced postprandial plasma triglycerides, chylomicron triglycerides, chylomicron cholesterol and chylomicron apo B-48; LDL particle size was significantly increased from baseline with vildagliptin. In accordance, the findings of this study revealed the significant effects of vildagliptin on lowering fasting blood glucose and glucagon levels, ameliorating the severity of insulin resistance and dyslipidemia. Moreover, combination of vildagliptin with pumpkin seed extract or gum Arabic led to great synergistic effects.

\section{Conclusions and future prospective}

Pumpkin seeds and gum Arabic ameliorate hyperglycemia, hyperlipidemia, and insulin resistance and reduce blood glucagon levels that indicate their antidiabetic effects. The possible mechanism of action of pumpkin seed as antidiabetic is summarized in affecting $\beta$-cell regeneration, insulin secretion, activities of enzymes involved in glucose metabolism, while gum Arabic acts through the viscosity effect of its fibers, obstructs carbohydrates digestion and inhibits glucose absorption in the intestine via interaction with the sodium-glucose transporter-1 (SGLT1). Combination of pumpkin seed extract or gum Arabic with vildagliptin provide more beneficial effects, better glycemic index and decrease risk of metabolic syndrome complications when compared with alone vildagliptin therapy.

\section{REFERENCES}

Adams GG, Imran S, Wang S, et al., 2014. The hypoglycemic effect of pumpkin seeds, Trigonelline (TRG), Nicotinic acid (NA) and D-Chiro-inositol (DCI) in controlling glycemic levels in diabetes mellitus. Critical reviews in food science and nutrition 54: 1322-1329.

Ahmed AA, Musa HH, Fedail JS, et al., 2016. Gum arabic suppressed diet-induced obesity by alteration the expression of mRNA levels of genes involved in lipid metabolism in mouse liver. Bioactive Carbohydrates and Dietary Fibre 7: 15-20.

Al-Majed AA, Mostafa AM, Al-Rikabi AC, et al., 2002. Protective effects of oral arabic gum administration on gentamicin-induced nephrotoxicity in rats. Pharmacol Res, 46: 445-451.

Al-Majed AA, Abd-Allah AR, Al-Rikabi AC, et al., 2003. Effect of oral administration of arabic gum on cisplatin-induced nephrotoxicity in rats. J Biochem Mol Toxicol, 17: 146-153.

Almohaimeed H, Amin H, El-Aziz G et al., 2018. Arabic gum acacia improves diabetic peripheral neuropathy in rats: a biochemical and histopathological evidence. Int J Basic Clin Pharmacol.

Babiker R, Elmusharaf K, Keogh MB et al., 2018. Effect of Gum Arabic (Acacia Senegal) supplementation on visceral adiposity index (VAI) and blood pressure in patients with type 2 diabetes mellitus as indicators of cardiovascular disease (CVD): a randomized and placebo-controlled clinical trial. Lipids Health Dis, 17: 56.

Bucolo G and David H, 1973. Quantitative determination of serum triglycerides by the use of enzymes. Clin Chem 19: 476-482. 
Burkey BF, Li X, Bolognese L, et al., 2005. Acute and chronic effects of the incretin enhancer vildagliptin in insulinresistant rats. J Pharmacol Experim Therap, 315: 688-695.

Caili F, Huan S and Quanhong L, 2006. A review on pharmacological activities and utilization technologies of pumpkin. Plant Foods Human Nutr, 61: 70-77.

Dar AH, Sofi S and Rafiq S, 2017. Pumpkin the functional and therapeutic ingredient: A review. Int J Food Sci Nutr 2: 165170.

de Castro UGM, Silva ME, de Lima WG, et al., 2013. Agedependent effect of high-fructose and high-fat diets on lipid metabolism and lipid accumulation in liver and kidney of rats. Lipids Health Dis, 12: 136.

Deacon CF and Holst JJ, 2013. Dipeptidyl peptidase-4 inhibitors for the treatment of type 2 diabetes: comparison, efficacy and safety. Expert Opin Pharmacother 14: 2047-2058.

El-Gayar KE, Ibrahim MA, Mohamed SH, et al., 2012. Application of extracted peroxidase enzyme from turnip roots (BRASSICA NAPUS) in clinical diagnostic kit. Int J Cur Res Rev 4.

Fridewald W, 1972. Estimation of the concentration of lowdensity lipoprotein cholesterol in plasma, without use of the preparative ultracentrifuge. Clin Chem, 18: 499-502.

Glew R, Glew R, Chuang LT, et al., 2006. Amino acid, mineral and fatty acid content of pumpkin seeds (Cucurbita spp) and Cyperus esculentus nuts in the Republic of Niger. Plant Foods Human Nutr, 61: 49-54.

Gohari Ardabili A, Farhoosh R and Haddad Khodaparast MH, 2011. Chemical composition and physicochemical properties of pumpkin seeds (Cucurbita pepo Subsp. pepo Var. Styriaka) grown in Iran. J Agric Sci Technol, 13: 10531063.

Ibrahim OB, Osman ME and Hassan EA, 2013. Characterization and simple fractionation of Acacia Senegal. J Chemica Acta 2: 11-17.

Keating GM, 2014. Vildagliptin: a review of its use in type 2 diabetes mellitus. Drugs, 74: 587-610.

Larner J, 2002. D-chiro-inositol-its functional role in insulin action and its deficit in insulin resistance. J Diab Res, 3: 4760.

Lattimer JM and Haub MD, 2010. Effects of dietary fiber and its components on metabolic health. Nutrients 2: 1266-1289.

Maeda S, Matsui T and Yamagishi S, 2012. Vildagliptin inhibits oxidative stress and vascular damage in streptozotocininduced diabetic rats. Int J Cardiol, 158: 171-173.

Marbun N, Sitorus P and Sinaga SM, 2018. Antidiabetic effects of pumpkin (Cucurbita moschata durch) flesh and seeds extracts in streptozotocin induced mice. Asian J Pharm Clin Res 11, 2018.

Matikainen N, Mänttäri S, Schweizer A, et al., 2006. Vildagliptin therapy reduces postprandial intestinal triglyceride-rich lipoprotein particles in patients with type 2 diabetes. Diabetologia 49, 2049-2057.

Mirghani ME, Elnour AA, Kabbashi N, et al., 2018. Determination of antioxidant activity of gum arabic: An exudation from two different locations. Sci Asia, 44: 179186.

Musa HH, Ahmed AA and Musa TH, 2019. Chemistry, Biological, and Pharmacological Properties of Gum Arabic. Bioactive Mol Food, pp: 797-814.

Nasir O, Babiker S and Salim A, 2016. Protective effect of gum Arabic supplementation for type 2 diabetes mellitus and its complications. Int J Multidiscip Curr Res, 4: 288-294.

Ozougwu J, Obimba K, Belonwu C et al., 2013. The pathogenesis and pathophysiology of type 1 and type 2 diabetes mellitus. J Physiol Pathophysiol, 4: 46-57.

Patel D, Kumar R, Laloo D et al., 2012a. Natural medicines from plant source used for therapy of diabetes mellitus: An overview of its pharmacological aspects. Asian Pacific J Trop Dis, 2: 239-250.

Patel D, Prasad SK, Kumar R et al., 2012b. An overview on antidiabetic medicinal plants having insulin mimetic property. Asian Pacific J Trop Biomed, 2: 320-330.

Penttilä I, Voutilainen E, Laitinen P et al., 1981. Comparison of different analytical and precipitation methods for direct estimation of serum high-density lipoprotein cholesterol. Scandinavian J Clin Lab Investig, 41: 353-360.

Sharma A, Sharma AK, Chand T, et al., 2013. Antidiabetic and antihyperlipidemic activity of Cucurbita maxima Duchense (pumpkin) seeds on streptozotocin induced diabetic rats. J Pharmacogn Phytochem 1, 108-116.

Stumvoll M, Goldstein BJ and van Haeften TW, 2005. Type 2 diabetes: principles of pathogenesis and therapy. The Lancet, 365: 1333-1346.

Wang D, Zhu W, Li J, et al., 2013. Serum concentrations of fibroblast growth factors 19 and 21 in women with gestational diabetes mellitus: association with insulin resistance, adiponectin, and polycystic ovary syndrome history. PloS one 8:e81190.

Wewer Albrechtsen NJ, Kuhre RE, Windeløv JA, et al., 2016. Dynamics of glucagon secretion in mice and rats revealed using a validated sandwich ELISA for small sample volumes. Am J Physiol Endocrinol Metab, 311: E302-E309.

Yadav M, Jain S, Tomar R, et al., 2010. Medicinal and biological potential of pumpkin: an updated review. Nutr Res Rev, 23: 184-190.

Yoshinari O, Sato H and Igarashi K, 2009. Anti-diabetic effects of pumpkin and its components, trigonelline and nicotinic acid, on Goto-Kakizaki rats. Biosci, Biotechnol Biochem, 73: 1033-1041.

Young DS and Friedman RB, 2001. Effects of disease on clinical laboratory tests, Vol 1. Amer Assn Clin Chem. 